\title{
Optical and Optically Stimulated Luminescence Properties of Ce-doped $\mathrm{CsCl}-\mathrm{CaCl}_{2}-\mathrm{ZnCl}_{2}$ Glasses
}

\author{
Gota Ito, ${ }^{*}$ Hiromi Kimura, Daiki Shiratori, Daisuke Nakauchi, \\ Takumi Kato, Noriaki Kawaguchi, and Takayuki Yanagida \\ Division of Materials Science, Nara Institute of Science and Technology (NAIST), \\ 8916-5 Takayama-Cho, Ikoma, Nara 630-0192, Japan
}

(Received October 6, 2021; accepted November 5, 2021)

Keywords: photoluminescence, $\mathrm{OSL}$, dosimeter, $\mathrm{ZnCl}_{2}$-based glass, cerium

The optical and optically stimulated luminescence (OSL) properties of Ce-doped 20CsCl$20 \mathrm{CaCl}_{2}-60 \mathrm{ZnCl}_{2}(\mathrm{CCZ})$ glasses were evaluated. All the Ce-doped $\mathrm{CCZ}$ glasses showed a broad emission peak at $370 \mathrm{~nm}$ upon excitation at $320 \mathrm{~nm}$, and the decay time suggested that the origin was the $5 \mathrm{~d}-4 \mathrm{f}$ transitions of $\mathrm{Ce}^{3+}$. After X-ray irradiation, the Ce-doped $\mathrm{CCZ}$ glasses showed OSL around $370 \mathrm{~nm}$ under stimulation at $400 \mathrm{~nm}$. All the glasses exhibited dose response functions with good linearity in the dynamic range of $0.1-10 \mathrm{~Gy}$.

\section{Introduction}

Dosimeters using storage phosphors temporarily store the energy of ionizing radiation in the form of trapped carriers, and the stored information can be read out as luminescence by external stimulation. The obtained luminescence stimulated by thermal and optical stimulation is called thermally stimulated luminescence (TSL) and optically stimulated luminescence (OSL), ${ }^{(1,2)}$ respectively. Radio-photoluminescence, in which the photoluminescence (PL) intensity increases with the radiation dose, has also been used for dosimetry. Such dosimeters have been used for various radiation measurements such as personal dose monitoring and also for imaging plates (IPs). ${ }^{(3)}$ In general, the characteristics required for dosimeter materials include high emission intensity, low fading, and proportionality between emission intensity and irradiation dose. In addition, while personal dose monitoring applications require an effective atomic number $\left(Z_{\text {eff }}\right)$ close to that of the human body in terms of bioequivalence $\left(Z_{\text {eff }}=7.29\right)$, based on the composition of $\mathrm{C}_{5} \mathrm{H}_{40} \mathrm{O}_{18} \mathrm{~N}$, ${ }^{(4)}$ IP applications such as dental diagnostics require a large $Z_{\text {eff }}$ for high detection efficiency. Various material forms such as single crystals, ${ }^{(5-7)}$ ceramics, ${ }^{(8-13)}$ and glasses ${ }^{(14,15)}$ have been investigated for dosimeter applications, and glasses have industrial advantages such as a low production cost and high moldability in comparison with single crystals and ceramics. ${ }^{(16)}$ However, only Ag-doped phosphate glasses have been commercially applied in practical use, ${ }^{(17,18)}$ and there have been only a few reports on the TSL and OSL properties of glasses with

*Corresponding author: e-mail: ito.gota.ia4@ms.naist.jp

https://doi.org/10.18494/SAM3681 
a large $Z_{\text {eff }}$ Therefore, there is still plenty of room for studying heavy glasses for dosimetric applications.

In recent years, we focused on $\mathrm{ZnCl}_{2}$-based glasses because of their large $Z_{\text {eff }}$ in comparison with oxide glasses such as $\mathrm{SiO}_{2^{-}}, \mathrm{P}_{2} \mathrm{O}_{5^{-}}$, and $\mathrm{B}_{2} \mathrm{O}_{3}$-based glasses. In addition, halide-based glasses have low phonon energy in comparison with oxide glasses. ${ }^{(19,20)}$ The low phonon energy of the host glass leads to a low thermal relaxation rate because more phonons are excited at the same time; therefore, various halide glassy phosphors have been evaluated owing to their high luminescence efficiency. ${ }^{(21-31)}$ In our previous studies, we investigated Eu- or Ce-doped $20 \mathrm{CsCl}-20 \mathrm{BaCl}_{2}-60 \mathrm{ZnCl}_{2}$ (CBZ) glasses and clarified that Ce-doped samples showed high PL quantum yields $(Q Y \mathrm{~s})$ of $75.7 \%{ }^{(32,33)}$ However, most previous studies on the dosimetric properties of glasses have examined the TSL and OSL properties of oxide glasses, ${ }^{(34-38)}$ and there have been no studies evaluating the OSL characteristics of $\mathrm{ZnCl}_{2}$-based glasses. In this study, we evaluated the OSL properties of Ce-doped $20 \mathrm{CsCl}-20 \mathrm{CaCl}_{2}-60 \mathrm{ZnCl}_{2}(\mathrm{CCZ})$ glasses for the first time, and the effects of doping on optical and OSL characteristics were also investigated.

\section{Materials and Methods}

$x \mathrm{CeCl}_{3}-20 \mathrm{CsCl}-20 \mathrm{CaCl}_{2}-60 \mathrm{ZnCl}_{2}(x=0.01,0.05$, and $0.1 \%)$ glasses (molar ratio) were prepared by the melt-quenching method. First, $\mathrm{CsCl}$ (99.99\%, Mitsuwa Chemicals), $\mathrm{CaCl}_{2}$ (99.9\%, High Purity Chemicals), $\mathrm{ZnCl}_{2}$ (99.99\%, Wako Chemicals), and $\mathrm{CeCl}_{3} \cdot 6 \mathrm{H}_{2} \mathrm{O}$ (99.99\%, High Purity Chemicals) were mixed and then placed in quartz ampules, with a total powder weight of $4 \mathrm{~g}$ for each sample. Then, the powders were dried under vacuum at $200{ }^{\circ} \mathrm{C}$ for $1 \mathrm{~h}$, and the dried powders were enclosed in an ampule under vacuum. Following the drying process, the powders were heated for $1 \mathrm{~h}$ at $700{ }^{\circ} \mathrm{C}$ using an electric furnace, and the sealed ampule was placed in water at room temperature to rapidly cool the melt. After that, the thickness of the obtained glasses was standardized to $1 \mathrm{~mm}$ by polishing the top and bottom surfaces using a variety of sandpapers (600-3000 grit).

The diffuse transmission spectra of the Ce-doped CCZ glasses were measured using a spectrophotometer (SolidSpec-3700, Shimadzu). The PL QY and excitation/emission maps were measured using a Quantaurus-QY spectrometer (C11347, Hamamatsu Photonics). PL decay curves were obtained using a Quantaurus- $\tau$ spectrometer (C11367 Hamamatsu Photonics). OSL emission and stimulation spectra of the Ce-doped $\mathrm{CCZ}$ glasses were obtained using a spectrofluorometer (FP-8600, JASCO) after X-ray irradiation (1 Gy). To obtain the OSL dose response functions, OSL spectra were measured using the spectrofluorometer after X-ray irradiation with various doses during stimulation at $400 \mathrm{~nm}$. Only the OSL properties were measured using the sample in a sealed ampule, while the other properties were evaluated using the polished samples. Because of the low chemical stability of the glass samples, each measurement except for OSL was performed within 10 min after taking them from a desiccator with silica gel. 


\section{Results and Discussion}

Figure 1 is a photograph of the as-prepared Ce-doped CCZ glasses in a quartz ampule. All glasses synthesized in the quartz ampule were colorless and transparent. These quartz ampules were crushed to obtain the samples, and some pieces of the samples were used in the following characterizations after polishing. Figure 2 shows the diffuse transmission spectra of the Cedoped CCZ glasses. The diffuse transmittance of all the prepared glasses was $50-60 \%$ in the wavelength range of 350-850 nm. A broad absorption band around 300-350 nm was observed, and the absorption became strong with increasing concentration of Ce. Since the Ce-doped glasses showed similar absorption bands at around $300-350 \mathrm{~nm}$ in a previous study, ${ }^{(39)}$ the origin of the bands was concluded to be the $4 \mathrm{f}-5 \mathrm{~d}$ transitions of $\mathrm{Ce}^{3+}$.

Figure 3 presents the PL excitation/emission contour plots of the Ce-doped CCZ glasses. All the Ce-doped CCZ glasses showed a broad emission band around $370 \mathrm{~nm}$ with an excitation band around $320 \mathrm{~nm}$. With increasing Ce concentration, the peak positions shifted to a longer wavelength, which is considered to be associated with self-absorption due to $\mathrm{Ce}^{3+}$. Since the excitation and emission shapes were similar to those of Ce-doped glasses in previous reports, ${ }^{(40,41)}$ the origin of the emission was ascribed to the $5 \mathrm{~d}-4 \mathrm{f}$ transitions of $\mathrm{Ce}^{3+}$. The PL $Q Y$ s of the $0.01,0.05$, and $0.1 \%$ Ce-doped CCZ glasses upon excitation at $320 \mathrm{~nm}$ were $75.6,87.6$, and $81.5 \%$, respectively. The PL QYs of the Ce-doped CCZ glasses were higher than that of a Cedoped CBZ glass $(\sim 76 \%)^{(32)}$ and comparable to that of a commercial GS20 Li-glass scintillator $(\sim 80 \%){ }^{(42)}$ Figure 4 shows the PL decay curves of the Ce-doped glasses monitored at $380 \mathrm{~nm}$ under excitation with a wavelength of $340 \mathrm{~nm}$. The decay curves of all the Ce-doped glasses were well approximated by a single exponential decay function. The decay time constants of the

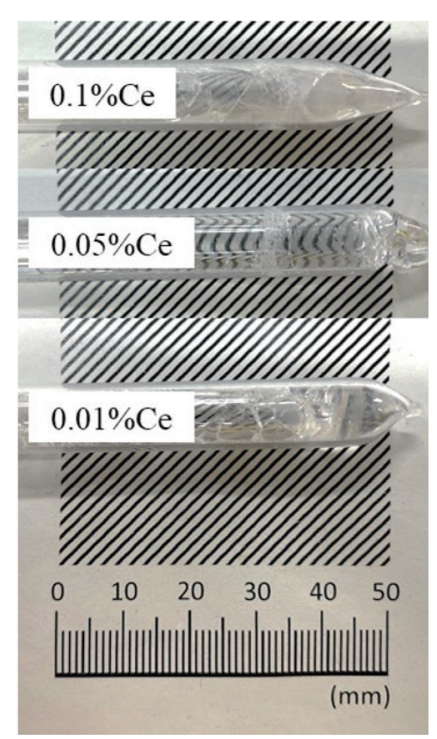

Fig. 1. (Color online) Synthesized CCZ glasses doped with various concentrations of $\mathrm{Ce}$.

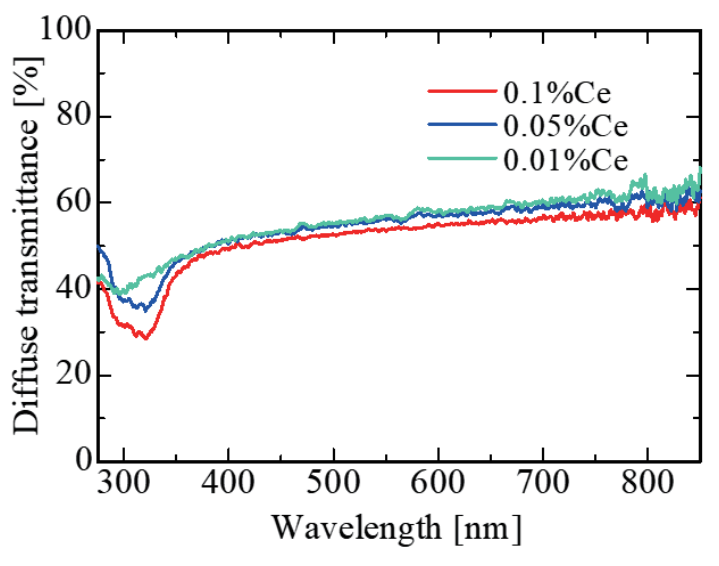

Fig. 2. (Color online) Diffuse transmittance spectra of Ce-doped CCZ glasses. 

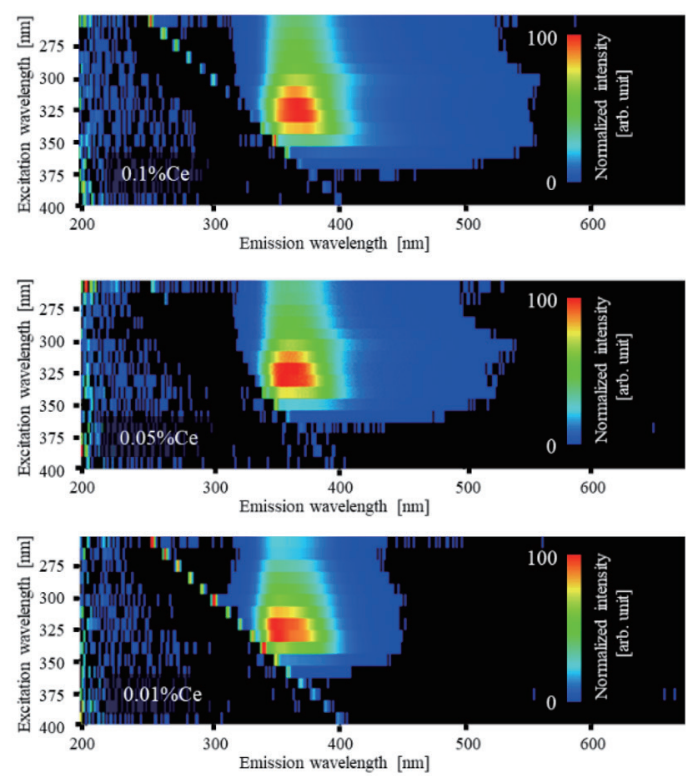

Fig. 3. (Color online) PL excitation/emission contour spectra of Ce-doped CCZ glasses. Top to bottom: $0.1,0.05$, and $0.01 \%$ Ce-doped samples.

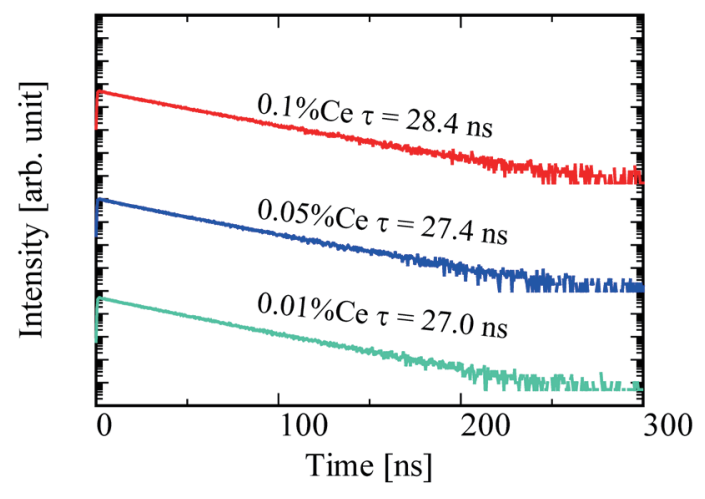

Fig. 4. (Color online) PL decay curves of Ce-doped $\mathrm{CCZ}$ glasses monitored at $380 \mathrm{~nm}$ under excitation at wavelength of $340 \mathrm{~nm}$.

CCZ glasses were 27.0-28.4 ns, which are also typical of 5d-4f transitions of $\mathrm{Ce}^{3+} \cdot{ }^{(15,43)}$ The decay time increased with increasing Ce concentration, and the concentration dependence was not consistent with that of PL QY. Such phenomena were also observed in Ce-doped CBZ glasses, ${ }^{(32)}$ and the reason for them is still unclear. One possible reason is that as the concentration increased, energy transfer between the emission centers occurred without nonradiative quenching, resulting in a delay of the decay.

Figure 5 illustrates the OSL spectra of Ce-doped CCZ glasses after X-ray irradiation of $10 \mathrm{~Gy}$. After the X-ray irradiation, all the samples showed OSL emission peaks at $370 \mathrm{~nm}$ under a stimulation wavelength of $400 \mathrm{~nm}$. Since the spectral shapes matched those of the PL spectra, the emission was caused by the $5 \mathrm{~d}-4 \mathrm{f}$ transitions of $\mathrm{Ce}^{3+}$. Among the prepared samples, the OSL intensity of the $0.05 \% \mathrm{Ce}$-doped $\mathrm{CCZ}$ was the highest. This observation is the first report of OSL from $\mathrm{ZnCl}_{2}$-based glasses. Figure 6 shows the OSL dose response functions of the Ce-doped CCZ glasses. All the glasses exhibited dose response functions with a good linear relationship in the range of 0.1-10 Gy. The detection limit of the Ce-doped CCZ glasses was worse than that of commercial dosimetric materials. In commercial OSL dosimeters and IPs, the read-out device has been optimized to enable the use of photodetectors as well as lasers for the stimulation light. Therefore, the detection limit of Ce-doped CCZ glasses may be improved by also optimizing the read-out device. The lowest detection limit of the glasses was lower than that of a practical glass badge of Chiyoda Ltd. (0.1 mGy). 


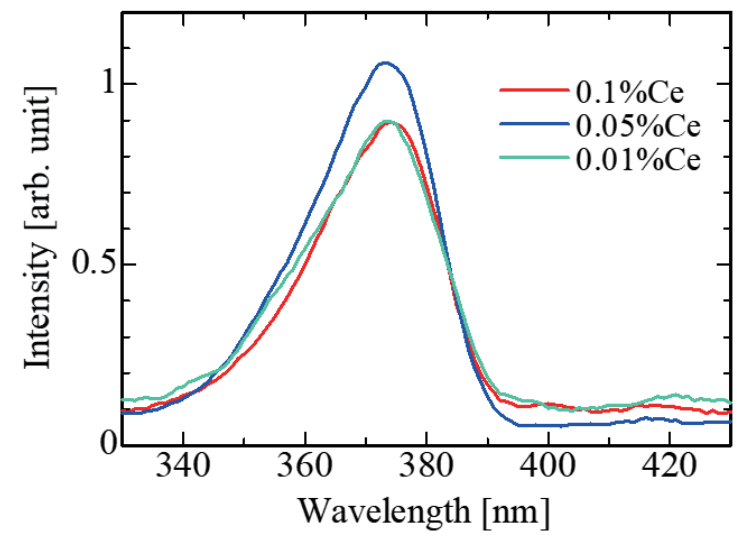

Fig. 5. (Color online) OSL spectra of Ce-doped CCZ glasses after X-ray irradiation of $10 \mathrm{~Gy}$.

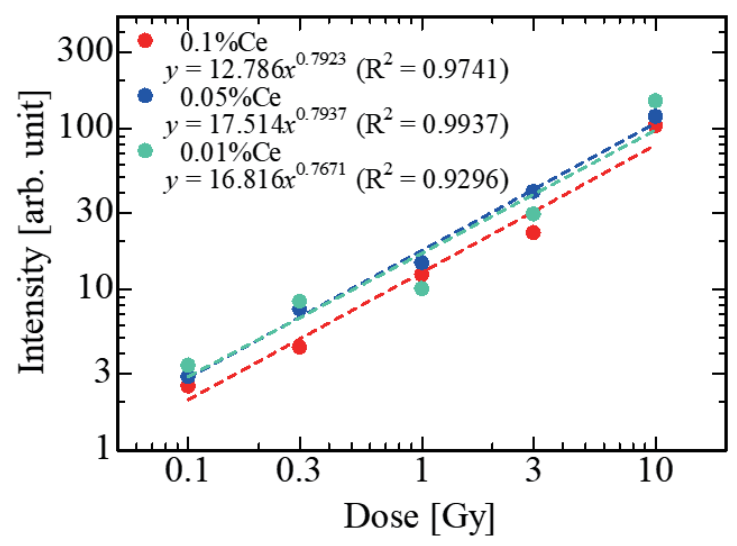

Fig. 6. (Color online) OSL dose response functions of Ce-doped CCZ glasses.

\section{Conclusions}

CCZ glasses doped with various Ce concentrations were synthesized, and the optical and OSL characteristics were evaluated. The Ce-doped CCZ glasses showed a broad emission band around $370 \mathrm{~nm}$ with an excitation band around $320 \mathrm{~nm}$ that originated from the $5 \mathrm{~d}-4 \mathrm{f}$ transitions of $\mathrm{Ce}^{3+}$. After $10 \mathrm{~Gy} \mathrm{X}$-ray irradiation, OSL peaks due to the $5 \mathrm{~d}-4 \mathrm{f}$ transition of $\mathrm{Ce}^{3+}$ were observed when the glasses were stimulated by light exposure at $400 \mathrm{~nm}$. The dose responses showed good linearity in the dynamic range of $0.1-10$ Gy. Although OSL has so far only been reported for oxide glasses, here, OSL was observed for the first time in chloride glasses. The dynamic range obtained in this study is insufficient for practical use, but we will improve the dynamic range by optimizing the composition of the material and the measurement conditions in the future.

\section{Acknowledgments}

This work was supported by Grants-in-Aid for Scientific Research B (19H03533, 21H03733, and 21H03736), Early-Career Scientists (20K20104), and JSPS Fellows (19J22091) from JSPS. The Cooperative Research Project of the Research Center for Biomedical Engineering, Nippon Sheet Glass Foundation, SEI Group CSR Foundation, TEPCO Memorial Foundation, KRF Foundation, and Murata Science Foundation are also acknowledged.

\section{References}

1 T. Yanagida, G. Okada, and N. Kawaguchi: J. Lumin. 207 (2019) 14.

2 G. Okada, K. Hirasawa, T. Yanagida, and H. Nanto: Sens. Mater. 33 (2021) 2117.

3 S. W. S. McKeever and M. Moscovitch: Radiat. Prot. Dosimetry 104 (2003) 263. 
4 C. A. Jayachandran: Phys. Med. Biol. 16 (1971) 005.

5 Y. Takebuchi, H. Fukushima, T. Kato, D. Nakauchi, N. Kawaguchi, and T. Yanagida: Sens. Mater. 32 (2020) 1405.

6 N. Kawaguchi, G. Okada, Y. Futami, D. Nakauchi, T. Kato, and T. Yanagida: Sens. Mater. 32 (2020) 1419.

7 H. Kimura, T. Kato, D. Nakauchi, M. Koshimizu, N. Kawaguchi, and T. Yanagida: Sens. Mater. 31 (2019) 1265.

8 R. Oh, S. Yanagisawa, H. Tanaka, T. Takata, G. Wakabayashi, M. Tanaka, N. Sugioka, Y. Koba, and K. Shinsho: Sens. Mater. 33 (2021) 2129.

9 D. Shiratori, T. Kato, D. Nakauchi, N. Kawaguchi, and T. Yanagida: Sens. Mater. 33 (2021) 2171.

10 H. Kimura, T. Kato, D. Nakauchi, N. Kawaguchi, and T. Yanagida: Sens. Mater. 33 (2021) 2187.

11 H. Kimura, T. Kato, D. Nakauchi, N. Kawaguchi, and T. Yanagida: Sens. Mater. 32 (2020) 1381.

12 D. Maruyama, S. Yanagisawa, Y. Koba, T. Andou, and K. Shinsho: Sens. Mater. 32 (2020) 1461.

13 D. Nakauchi, G. Okada, and T. Yanagida: J. Ceram. Soc. Japan 124 (2016) 546.

14 T. Kato, D. Shiratori, M. Iwao, H. Takase, D. Nakauchi, N. Kawaguchi, and T. Yanagida: Sens. Mater. 33 (2021) 2163.

15 D. Nakauchi, G. Okada, Y. Fujimoto, N. Kawano, N. Kawaguchi, and T. Yanagida: Opt. Mater. 72 (2017) 190.

16 Z. Zhu, B. Liu, C. Cheng, Y. Yi, W. Guo, S. Huang, H. Chen, M. Gu, C. Ni, and X. Liu: Opt. Mater. 35 (2013) 2343.

17 Y. Miyamoto, T. Yamamoto, K. Kinoshita, S. Koyama, Y. Takei, H. Nanto, Y. Shimotsuma, M. Sakakura, K. Miura, and K. Hirao: Radiat. Meas. 45 (2010) 546.

18 H. Nanto, Y. Miyamoto, T. Oono, Y. Takei, T. Kurobori, and T. Yamamoto: Procedia Eng. 25 (2011) 231.

19 M. Shojiya, Y. Kawamoto, and K. Kadono: J. Appl. Phys. 89 (2001) 4944.

20 J. Qiu, K. Kojima, A. Kubo, M. Yamashita, and K. Hirao: Soc. Glas. Technol. 41 (2000) 150.

21 T. Tsuneoka, K. Kojima, and S. Bojja: J. Non. Cryst. Solids 202 (1996) 297.

22 T. Kishimoto, N. Wada, and K. Kojima: Phys. Chem. Glas. 43 (2002) 233.

23 M. Shojiya, M. Takahashi, R. Kanno, Y. Kawamoto, and K. Kadono: J. Appl. Phys. 82 (1997) 6259.

24 B. Dussardier, J. Wang, D. C. Hanna, and D. N. Payne: Opt. Mater. 4 (1995) 565.

25 P. J. Dereń, M. Karbowiak, J.-C. Krupa, and J. Drożdżyński: J. Alloys Compd. 275-277 (1998) 393.

26 K. Annapurna, R. N. Dwivedi, P. Kundu, and S. Buddhudu: Mater. Res. Bull. 38 (2003) 429.

27 K. Annapurna, R. N. Dwivedi, and S. Buddhudu: Mater. Lett. 53 (2002) 359.

28 N. Wada and K. Kojima: J. Am. Ceram. Soc. 85 (2004) 590.

29 M. Shojiya, M. Takahashi, R. Kanno, Y. Kawamoto, and K. Kadono: Appl. Phys. Lett. 65 (1994) 1874.

30 N. Wada, T. Tsuneoka, and K. Kojima: J. Am. Ceram. Soc. 85 (2002) 1396.

31 A. Gharavi and G. L. McPherson: Appl. Phys. Lett. 61 (1992) 2635.

32 G. Ito, H. Kimura, D. Shiratori, D. Nakauchi, T. Kato, N. Kawaguchi, and T. Yanagida: Optik 226 (2020) 165825.

33 G. Ito, H. Kimura, D. Shiratori, K. Hashimoto, D. Nakauchi, M. Koshimizu, T. Kato, N. Kawaguchi, and T. Yanagida: J. Mater. Sci. Mater. Electron. 32 (2021) 8725.

34 D. Shiratori, H. Masai, T. Kato, G. Okada, D. Nakauchi, N. Kawaguchi, and T. Yanagida: Sci. Rep. 10 (2020) 21403.

35 K. Hashimoto, D. Shiratori, T. Matsuo, T. Kato, D. Nakauchi, N. Kawaguchi, and T. Yanagida: J. Mater. Sci. Mater. Electron. 31 (2020) 17755.

36 D. Shiratori, D. Nakauchi, H. Fukushima, T. Kato, N. Kawaguchi, and T. Yanagida: Opt. Mater. 105 (2020) 109895.

37 H. Kimura, H. Masai, T. Kato, D. Nakauchi, N. Kawaguchi, and T. Yanagida: J. Mater. Sci. Mater. Electron. 31 (2020) 3017.

38 D. Nakauchi, K. Shinozaki, N. Kawaguchi, and T. Yanagida: Optik 185 (2019) 812.

39 H. Kimura, F. Nakamura, T. Kato, D. Nakauchi, G. Okada, N. Kawaguchi, and T. Yanagida: Sens. Mater. 30 (2018) 1555.

40 D. Shiratori, D. Nakauchi, T. Kato, N. Kawaguchi, and T. Yanagida: Sens. Mater. 32 (2020) 1365.

41 W. Chewpraditkul, Y. Shen, D. Chen, B. Yu, P. Prusa, M. Nikl, A. Beitlerova, and C. Wanarak: Opt. Mater. 34 (2012) 1762.

42 N. Kawaguchi, N. Kawano, G. Okada, and T. Yanagida: Sens. Mater. 29 (2017) 1431.

43 T. Oya, D. Nakauchi, G. Okada, N. Kawaguchi, and T. Yanagida: Nucl. Instrum. Methods Phys. Res., Sect. A 866 (2017) 134. 